\title{
Think outside the book: Transformative justice using children's literature in educational settings
}

\author{
Divya Anand ${ }^{1} \&$ Laura M. Hsu ${ }^{2}$
}

1. Corresponding author

Cambridge College, Department of Early

Education and Care, MA, Boston, USA

E-mail: divya.anand@go.cambridgecollege.edu

2. Merrimack College, Department of Education and Community Studies, North Andover, MA, USA

\section{Article Info}

Received: April 1, 2020

Revised: September 21, 2020

Accepted: September 25, 2020

\section{$10.46303 /$ jcsr.2020.13}

This is an Open Access article distributed under the terms of the CC BY 4.0 International license. (https://creativecommons.org/licenses/by/4.0/)

\section{How to cite}

Anand, D. \& Hsu, L. M. (2020). Think outside the book: Transformative justice using children's literature in educational settings. Journal of Curriculum Studies Research, 2(2), 122-143. https://doi.org/10.46303/jcsr.2020.13

\section{ABSTRACT}

Using Alexis Jemal's conceptualization of transformative potential, founded on Paulo Freire's idea of Critical Consciousness, a guiding transformative justice approach and accompanying questionnaire are provided here that can be adapted into any existing early childhood or elementary curriculum for children. The approach provides teachers with a methodology to search for new books and resources and use existing ones to foster their own and their students' critical social consciousness. The transformative justice approach has two objectives: one, to enable teachers to help understand, guide, and mediate differences in the context of equity and social justice; and two, to equip children with social awareness and critical consciousness to identify stereotypes and biases, and to build solidarities between and among themselves. The transformative justice approach does not actively avoid books or resources with stereotypes or biases, but seeks to build skill sets in children and teachers to recognize and counter biases and stereotypes using texts as learning tools. It synthesizes and builds on anti-bias and culturallysensitive pedagogies to intentionally center structural and systemic inequities, as well as fosters social awareness and critical thinking in both teachers and students by reimagining the classroom as a collaborative learning space.

\section{KEYWORDS}

Transformative justice; Critical social consciousness; Children's literature; Anti-bias; Equity; Social justice 


\section{INTRODUCTION}

"I have never encountered any children in any group who are not geniuses. There is no mystery on how to teach them. The first thing you do is treat them like human beings and the second thing you do is love them." -Dr. Asa Hilliard

Children develop consciousness of differences, including that of race and skin tones, between six to 10 months, and begin showing racial preferences as early as four years of age (Baron \& Banaji, 2006; Dunham et al., 2013; Raabe \& Beelmann, 2011; Williams \& Steele, 2019). The meanings, associations, and judgments that children correlate with people are drawn from their environment, which encompasses families, media, school, and community. Children and adults learn from the contexts they are embedded in, which inform each other, and show explicit and implicit biases that are learned from the environment (Over \& McCall, 2018). Research shows how implicit bias impacts children who are African American, Black, Indigenous, People of Color $(A B I P O C)^{1}$ starting in preschool classrooms (Gilliam et al., 2016; Skiba, 2015; Skiba et al., 2011). This finding also aligns with school disciplinary data that indicate ABIPOC students are disproportionately disciplined in comparison to their white counterparts (McNeal, 2016; US House of Representatives, 2019; Welsh \& Little, 2018). The preschool to prison pipeline is one of the tangible manifestations of bias that speaks to the gap between the promise of education and its disparate outcomes (Anand, 2020; Gilliam et al., 2016).

The idea of what constitutes as an infraction in the classroom is chiefly dependent on the beliefs, implicit and explicit biases, and stereotypes held by the teacher, and plays a key role in the preschool to prison pipeline (Carter et al., 2017; Gullo, 2017; McNeal, 2016; Staats, 2014). It is also pertinent to note that according to the National Center for Education Statistics for 20152016, 81 percent of all public elementary and secondary school students in the U.S. were nonWhite. In contrast, teachers who identified as ABIPOC make up only 20 percent of the teaching workforce in public schools (National Center for Education Statistics, 2017). As disciplinary measures are initiated based on teacher judgment, and given the gap between the demographic composition of public school teachers and students, the association among race, implicit bias, and school discipline need to be considered. In fact, several studies have pointed to the connections between racial stereotypes and biases, and cultural dissonance between students and teachers contributing to disproportionate discipline outcomes (Fabelo et al., 2011; Golann, 2015; Gregory \& Mosely, 2004; Gregory \& Thompson, 2010; Howard, 2001; Okonofua \& Eberhardt, 2015; Skiba, 2015; Skiba et al., 2011; Staats, 2014). Conversely, it becomes crucial to examine the relationship between school discipline and academic performance to interrogate the current US public school system's capacities to nurture and support the holistic development of ABIPOC students.

\footnotetext{
${ }^{1}$ We add African American to the beginning of Black Indigenous People of Color (ABIPOC) to acknowledge people who are Americans of African origin whose ancestors were enslaved, as opposed to Black, which includes people from African countries who have immigrated to the US. One " $A$ " instead of two are used at the beginning of the acronym for sake of brevity.
} 
Within this education system, disproportionate disciplinary outcomes, leading to students missing instruction in the classroom, directly contribute to the achievement gap, or the disparity in the academic outcomes of ABIPOC students and low-income students in comparison to their counterparts (Gregory et al., 2010; Morris \& Perry, 2017). Discrimination based on race and ethnicity toward ABIPOC students triggers psychological and biological responses to these stressors, which has manifold impacts on learning. These stressors negatively impact motivation levels and cognitive processes such as attention, memory, and executive functioning, all of which are associated with academic achievement (Heissel et al., 2017; Levy et al., 2016). The correspondence between school discipline and racial differences in achievement point to multiple, intersecting factors operating inside and outside of the school system.

For children belonging to the global majority, contextualizing differences based on social equities or inequities help them to not internalize discrimination as an experience they deserve or due to a deficit in them. It creates a sense of identity, consciousness, and agency that enable them to speak and act for themselves, and be who they are. For others, exposure to differences steers them clear from a false sense of ethnocentric pride and also "normalizes" differences in others, to identify inequities and use their platforms to amplify the voices of historically disenfranchised communities. In this context, it is important to create narratives and curricula that depict the full humanity of people, for both children who belong or do not belong to disenfranchised communities, as we aim for structural and systemic change in our education system.

A consequent factor to examine is how observing and imbibing teacher behavior influences children's self-perception and their perception of other children in early childhood and elementary classrooms. As Bettina Love (2014) reiterates for children of color ${ }^{2}$ in schools, it leads to Spirit murdering, a term coined by legal scholar Patricia Williams (1991), which is "the personal, psychological, and spiritual injuries to people of color through the fixed, yet fluid and moldable, structures of racism, privilege, and power" (p. 302). Instilling a positive social and racial identity in ABIPOC children, and bolstering their ability to withstand and counter the social, emotional, psychological, and cognitive effects of racism, becomes imperative.

As stated earlier, the onset of the school to prison pipeline is identified in early childhood classrooms (Edelman, 2006; Goff et al., 2014). Countering and re-imagining the gaps in both discipline and achievement in early childhood and elementary classrooms then needs to take a multidimensional and proactive approach. The approach needs to be multidimensional because for teachers to foster academic, social, and emotional development of children, awareness of the systemic and structural barriers that inhibit the learning and well-being of all students is key, as much as individual micro-level factors within the classroom.

\footnotetext{
${ }^{2}$ We wish to preserve the original reference that Love (2014) uses for "children of color" and thus do not reference ABIPOC here.
} 


\section{Critical Social Consciousness and Transformative Justice}

Founded on Paulo Freire's (2000) idea of Critical Consciousness, Alexis Jemal (2017) puts forth the notion of transformative potential in urban educational spaces to transform oppressive, discriminatory spaces into equitable, just, and liberating spaces for all students. Jemal offers three goals of transformative potential:

(1) to objectify and address issues of systemic inequity, (2) to produce an informed and civically engaged student body with the capacity to transform individuals, families, communities, institutions, and sociopolitical systems, and (3) to raise the critical consciousness of educators who are responsible for producing the leaders of the future. (p. 18)

Transformative change and action for teachers start with creating awareness of explicit and implicit biases at the individual level. At the systemic level, understanding the disparate educational outcomes for children due to structural inequities, and being mindful of the intersecting nature of power and privilege that underpin social hierarchies is also vital. Developing critical consciousness and incorporating practices rooted in social justice within the classroom, to critically reflect, question, challenge, and transform, is the next step. It involves both critical consciousness and critical reflection to engage in dialogue that causes discomfort, to understand and recognize inequities, and to take action. In this sense, critical consciousness leading to transformative potential also breaks free from the oppressed/oppressor binary as it recognizes people with different permutations and combinations of privilege and disempowerment at the same time. This understanding frees the onus of transformative potential as the sole responsibility of those who are identified as the oppressor or the oppressed. Freire (2000) calls for solidarity, asking the oppressor to "enter into the situation of those with whom one is in solidarity" (p. 49). Jemal (2017) identifies this as the "radical posture of empathy" (p.15), whereby the oppressed and oppressor must collaborate to transform the structures that beget oppression. Taking into account the overrepresentation of white individuals who identify as female in the teaching workforce, this conceptualization opens up greater possibilities for solidarity in bringing transformative change by rejecting onedimensional bracketing of individuals based on singular identity markers, be it on the basis of oppression or privilege.

In this context, the concept of intersectionality-often used to denote the presence of multiple dimensions of oppression based on an individual's multiple identities-is pertinent. Kimberlé Crenshaw's (1990) original conceptualization of intersectionality, used to frame the multiple dispossessions of African-American women based on race and gender, focused on transformative and counter-hegemonic knowledge production. However, as Sirma Bilge (2013) cautions, the "superficial deployment of intersectionality undermines intersectionality's credibility and potentials for addressing interlocking power structures and developing an ethics of non-oppressive coalition-building and claims-making" (p. 408). While using intersectionality 
helps circumvent defining individuals based on singular in-group identities, it is critical to use this term without depoliticizing it and by factoring in historical and structural inequities that mark the experiences of individuals as intersectional. It is with this understanding that we use the term "intersectionality," to be bound by radical transformative action that develops critical consciousness of structural, systemic, and historical inequities in education and to move towards transformative change. This rationale is not to blame or stereotype white teachers, but to underscore the fact that they are the most likely to teach ABIPOC children, and the least likely to share common ground with them. They have the potential to create significant and affirmative cross-social interactions, while serving as role models for white children, and influencing the perception of all children about themselves and each other (Allen \& WhiteSmith, 2015). It, again, follows Freire's (2000) interpretation of the teacher-student relationship as one of co-learning, where teachers are facilitators who engage in a non-hierarchical relationship with their students, model how to challenge the dominant social status quo leading to transformation, and engage in a process of co-creating knowledge through multiple methods and dialogical practices (Freire, 2000; Jemal, 2017; Smith-Maddox \& Solórzano, 2002).

In the classroom, teachers become the primary and active participants in developing critical consciousness and transformative potential for themselves, as much as they facilitate and develop the same for their students. The transformative justice approach is about consciously mediating meanings for children that are socially and historically grounded to help them understand differences in ways that counter stereotypes and negative biases, be it about themselves or others different from them. Regardless of the curriculum, book, or medium where students are exposed to a stereotype or stereotyped narrative, students are able to identify and question the stereotype, moving towards transformative action. While culturally aware pedagogies are incorporated in classrooms, it is crucial to not consider such pedagogies as a substitute for equity-oriented transformation (Gorski, 2019; Gorski \& Pothini, 2018). At the same time, the ability to constantly question and rethink the teacher's own understanding in light of new information is necessary to build on this foundation of transformative potentialone that is rooted in the knowledge of bias, prejudice, human rights, and ideas of fairness and justice. This critical thinking ability grounded in social awareness is crucial as transformation is a constant process, since messages embedded in books, television, media, and the external environment continuously contribute to the ways in which stereotypes and biases, both implicit and explicit, get embedded in students' consciousness (Over \& McCall, 2018).

This approach allows both teachers and children to explore the ways in which stereotypes are created and the arbitrary ways in which they get embedded in the collective social psyche. ABIPOC remain underrepresented in children's literature, including school curricula and, even if represented, they are often portrayed in stereotypical and unidimensional ways (Cooperative Children's Book Center, 2019). Children's books are used as tools to build a transformative justice lens while revisiting and revising existing curriculum. In using this approach, teachers learn how to use books to foster critical social consciousness by centering 
differences - to critically engage students on the different aspects of power and privilege made both visible and invisible within them.

The transformative justice approach scaffolds critical thinking prompts that allow for intersectional understandings, untangling deficit and stereotyped subtexts, and a metacognitive understanding of social contexts, including racism and privilege. Building on critical selfreflection, this approach uses a diffractive method and practice. Diffraction involves reading insights through one another "in ways that help illuminate differences as they emerge: how differences get made, what gets excluded, and how these exclusions matter" (Barad, 2007, p. 30). By placing the teacher at the center of the educational experience via self-reflection, diffractive practices allow for transformative shifts in pedagogy. As Cher Hill (2017) notes, teachers can be anchored as "nomadic" entities in order "to embrace a fluid and emergent sense of self, embrace difference and interference, while setting up pedagogical camps from time to time, and returning to familiar routes on a regular basis" (p. 9). This allows for the binaries of student-teacher to be disrupted and position them both with equal agency as "intra-acting bodies" (p. 8) that foster co-learning.

\section{TRANSFORMATIVE JUSTICE QUESTIONNAIRE}

Building upon the research of equity literacy and anti-bias educators, such as Derman-Sparks (2013), Gorski and Pothini (2018), Reese (2006), and York (2016), the authors created the following questionnaire, intended for educators and caretakers, to apply the transformative justice approach. The questionnaire serves as a guide for selecting books and facilitating discussions about books with children. One major distinction between prior approaches and the transformative justice approach is to address stereotypes in books as critical learning moments for both teacher and students, rather than shielding students from books with any stereotypes.

The transformative justice questionnaire supports teachers in foregrounding conversations around diversity, equity, and social justice on a variety of identity markers, including race, poverty and socioeconomic status, religion, ethnicity and culture, hair diversity, immigrant status, language diversity, disabilities, sex and gender, sexual orientation, and family composition. Although questions specific to distinct identity markers are included in the questionnaire, there may be multiple identities that are salient or not salient in any given context. Characters have multidimensional identities, and often what is left unsaid and outside the text speaks as much to the story as what is within the story. Thus, a combination of the following questions can be used while reading, and to discuss how various aspects of identity can impact a person's experience differently. Context is an equally important character in every story, as it situates a character within a particular time period, region, and cultural milieu, and within specific institutional structures. It is, then, impossible to ignore the transactional relationship between the environment and oneself on identity development and the reactions of others. 
Finally, it is important to note that this questionnaire will continue to evolve with new insights and socio-historical contexts. As with many aspects of equity and social justice, the process of asking critical questions and gaining insights is open-ended and time- and contextdependent. Nevertheless, the authors hope this questionnaire can be a starting point for developing a transformative justice approach.

\section{General Questions}

- Who seems to be the intended audience for this book?

- How would this book look different to varied audiences?

- Are the author and the illustrator able to speak to the experience depicted in the story, or does the story seem to be written by an outsider looking in?

- If the author's lived experiences speak to the major parts of the story (\#ownvoices story), are there parts of the story that are not representative of the author's lived experiences? If so, how do we address cultural misrepresentation in this context?

- Is one character from a particular socio-cultural background depicted as the spokesperson for that experience or socio-cultural background?

- Does the book use an "us" vs. "them" dichotomy, either overtly or covertly (those who belong versus those who don't, as something "special" and hence "different")?

- Is the book's message essentially "we are all different but the same," without acknowledging or addressing how these differences may mean inequitable and disparate experiences for "different" people, and that the conditions that create those "inequities" still persist?

- Does the book, in any way, depict inclusion as going out of the way to make "changes/accommodations" for a particular character(s)?

- Do the illustrations in the book contain stereotypical images or caricatures (e.g., exaggerated features of characters)?

- How do the illustrations in the story impact the message of the story?

- Are characters depicted as "different" put in the spotlight in a way that forces them to overtly or covertly efface their identity markers? Subsequently, do characters feel compelled to change their behavior or hide parts of their identity to belong in the story?

\section{Poverty and Socio-economic Status}

- Are the characters from lower socio-economic statuses depicted as African American Black Indigenous People of Color (ABIPOC), and does the book overtly or covertly imply that lower income families or children can overcome poverty by hard work (or conversely, that it is their lack of hard work that is the cause of their poverty)?

- How does the book depict the ways in which families can "rise out" of lower socioeconomic statuses? Does it pathologize families or communities experiencing poverty? 
- Are ABIPOC characters or other characters presented as "trouble-makers" for speaking up or advocating for themselves or others?

- Does it allow a conversation on systemic and structural barriers?

\section{Religion}

- What religion is depicted as "normal" and "accepted" in the story?

- Are there assumptions made in the story about religions or religious practices? If yes, how true or nuanced are those depictions?

- How would the book occur to children/families who do not follow any religion?

\section{Ethnicity and Culture}

- Are particular cultural celebrations depicted without addressing the sociohistorical reality of the community depicted and the inequities they may continue to face?

- Are cultural markers depicted as "costumes," "mascots," or conflated with general "stereotypes," including those of food, celebrations, dressing, etc.?

- When pointing to "multicultural" celebratory plotlines, does the book speak of ethnic heritage that is easily traceable/identifiable for everyone? For example, there may be African American, transracial adoptee, or multi-racial children who may not be able to trace their ethnic lineage.

\section{Race}

- In what ways are "whiteness" normalized as the status quo in the book? Or, conversely, how does the story break "whiteness" as the status quo?

- Are black or shades of brown, for both people and the color, equated with negative traits or values, such as dirty, evil, or lazy?

- Is white, both people and the color, associated with beauty, cleanliness, goodness, etc.?

\section{Hair Diversity}

- What kind of hair is portrayed as "the" beauty standard?

- Does the book "normalize" different types of hair?

- Are different kinds of hair, depicted as needing different kinds of care, accurately represented without one being portrayed as preferable over another?

- Does the book overtly or covertly reference the ways in which African American/Black hair continues to be policed and demonized in society?

- Is there a value judgement placed on natural hair versus coiffed/treated hair? 


\section{Immigrant Status}

- How are differences framed (e.g., immigrants as "foreign" or "illegal" based on human-made, arbitrary borders with immigration policies often stemming from racism)?

- Are all the immigrant characters' experiences deemed the same? Is there a value attached or a glorification of "non-immigrant" characters who accept differences?

- Is the immigrant or refugee experience portrayed in a deficit manner, such that the immigrant or refugee arrives to only "gain" opportunity and, in turn, prevents looking at their culture and presence as an asset?

\section{Language Diversity}

- What language is presented as the standard or the preferred language?

- Are people speaking languages other than English portrayed as "lacking" without fluency in English?

- Are words in other languages depicted as "unusual" or "exotic," or are they integrated within the context of the book?

- Is speaking more than one language depicted as an asset or a deficit?

- Is speaking certain languages, such as French, seen more favorably than speaking other languages, such as Arabic, Spanish, or Hindi?

- How are different registers or dialects of English depicted? For example, does a book centering African-American experiences use African-American Vernacular English (AAVE) with pejorative connotations?

- Does the story or the narrative involve tone policing, where the use of dialectical or colloquial variations are depicted negatively?

- Are stories about a particular community written in standard English? Are the words/text used, reflective of the cultural-linguistic variations associated with a community?

\section{Disabilities}

- What is the standard or basis from which acceptance is measured?

- Does the plot celebrate overcoming the adversity of having a disability as inspirational for people without disabilities? Who seems to be the intended audience?

- Is "inspiration" drawn from a person with disabilities who is striving to be like an "able-bodied" person, which re-establishes able-bodiedness as an asset and disability as a deficit?

- Is the aim of the story to invoke guilt in people without disabilities to try harderfor example, "if X (who is on a wheelchair) can do it, so can you"? Here, the onus is 
for people without disabilities to either get inspired, or to feel compelled to strive more, using people with disabilities as examples.

\section{Gender}

- Does the book serve to neutralize the pressure to conform to particular gender identities aligning with accepted gender expressions?

- What genders are "normalized" in the book and accepted?

- How would the book impact a child who does not identify along the traditional gender binary or the gender depicted in the book?

- Do the characters depicted in the book conform to or break off from traditional "gender" roles?

\section{Sexual Orientation}

- In what ways does the book characterize heterosexuality as normative (for example, that all families consist of a mother and father only)?

- What other social identities intersect with each character's sexual orientation, and how does that affect their lived realities?

\section{Family Composition}

- Does the book depict family structures as something that can change over time (e.g., new sibling(s), divorce, loss, blended families)?

- How far does the plot allow the reader to think about family compositions other than dual-parent households and heteronormative couples as parents?

- Apart from heteronormative, cisgender characters, does the book feature diverse representation in terms of race, disabilities, gender expressions/identities, etc.?

\section{Allyship}

- Is it clear from the plot, who is oppressed and why?

- Do the ally character/s stand in solidarity with the oppressed character, despite a risk to themselves?

- Is the onus placed on the "oppressed" character to change themselves to be more "likeable" and to not be bullied/harassed?

- Is the reason (often it's the "difference" from the rest of the group) for being harassed/bullied presented as a character flaw or a physical disability? Is this addressed in the book?

- What is the role, if any, of the adults in the book? Do any adults witness or, worse, take part in the oppression? Are they merely observant, or do they intervene when they observe an oppressive act?

- Are the bully/harasser characters in the book held accountable at some point? Does the corrective action seem adequate for what happened? 
To illustrate how the Transformative Justice Questionnaire can be used for diffractive reading, and to critically reflect on children's literature, some examples are provided here.

\section{The Colors of Us by Karen Katz (1999)}

A widely used children's book in anti-bias curricula is The Colors of Us, written and illustrated by Karen Katz (1999). The book is about a seven-year-old child named Lena, who first introduces herself and says she is the color of cinnamon. She next describes her mother's skin color, also analogous to a food, as French toast, and narrates that her mother is teaching her how to mix colors. Her mother explains that if the colors are mixed in the right combination, it will result in Lena's skin color. Lena replies that she thinks she simply has brown skin, which her mother refutes by saying there are a lot of shades of brown. Lena's mother then suggests they go for a walk so she can illustrate her point. On their walk, Lena's mother points out the various shades of skin colors they observe and makes a comparison to food for each person. The intention to normalize a spectrum of skin colors, and to celebrate the uniqueness of one's skin color with a seemingly lighthearted and accessible comparison, are some of the reasons this book appeals to many. However, the book inadvertently reinforces stereotypes in its depiction of some of the characters associated with food. For example, Mr. Pellegrino, who works in a local pizza parlor-which is stereotypical in and of itself--is described as having skin the color of "pizza crust, a golden brown". Thereafter, Mr. Kashmir, who sells spices in Lena's mother's favorite store, is the color of "ginger and chili powder". This is especially fraught given the colonial stereotyping of the word curry, which is used to refer to the many gravy-like dishes made with a mix of spices, including ginger and chili powder, in different proportions. There is no one dish called curry, and the term was coined by the British to give a homogenized name for a variety of south Asian dishes (Maroney, 2011). The "curry smelling" Indian immigrant or the stindian, a conflation of the stinky Indian immigrant, is a common racist stereotype and, as Madhavi Mallapragada (2016) notes, "curry marks the outsider status of the [south Asian] immigrant not just within the 'national' framework ('Indian not American') but also within the racial hierarchies of American culture ('not white' and not a desirable 'ethnic' group within multicultural United States)" (p. 265). Therefore, Mr. Kashmir, named after the disputed territory of Kashmir in the Indian subcontinent, looking like "ginger and chili powder" in the story, becomes problematic. Essentializing skin color to stereotypical foods is a double affront--not only does it caricature certain skin colors and nationalities, but by comparing black and brown skin color to food, it implies it is something to be consumed, and thus also feeds into the oversexualization and fetishization of Black and Brown women and children (Benard, 2016).

Without looking at The Colors of Us with a critical eye, it is tempting to accept the book at face value, so to speak, and see only the superficial merits of the diverse array of colors of people's skin. However, a transformative justice approach reveals entrenched stereotypes and a trivialization of describing one's skin color. Addressing the following questions in the Transformative Justice Questionnaire reveals such misrepresentations: "How would this book 
look different to varied audiences?"; "Does the book use an "us" vs. "them" dichotomy, either overtly or covertly (those who belong versus those who don't, as something "special" and hence "different")?"; "Is the book's message essentially 'we are all different but the same,' without acknowledging or addressing how these differences may mean inequitable and disparate experiences for 'different' people, and that the conditions that create those 'inequities' still persist?"; "Do the illustrations in the book contain stereotypical images or caricatures (e.g., exaggerated features of characters)?"; and "How do the illustrations in the story impact the message of the story?"

\section{Parker Looks Up: An Extraordinary Moment by Jessica Curry (2019)}

The much-awaited Parker Looks Up: An Extraordinary Moment, written by Jessica Curry (2019) and illustrated by Brittany Jackson, is another book that lends itself to a diffractive analysis with the transformative justice approach. Parker Looks Up was inspired by real life events in 2018, when 2-year-old Parker Curry visited the National Portrait Gallery in Washington, D.C., with her mother, sister, and best friend. Amy Sherald's portrait of former first lady Michelle Obama led to the viral photograph, a visit with Michelle Obama, and, eventually, Jessica Curry's book. The snapshot of a young, Black girl looking up in awe at an African American woman whose portrait was as large as her stature and influence, captivated many, and the book quickly rose to best seller lists. There was one overlooked depiction, however, that caught the eye of Debbie Reese (2019) of Nambé Pueblo and founder of American Indians in Children's Literature (AICL) blogspot. Reese points out a page spread in Parker Looks Up of a portrait of American Indians ${ }^{3}$ at the National Portrait Gallery. The portrait titled, "Young Omahaw, War Eagle, Little Missouri, and Pawnees," was painted by Charles Bird King in 1821. The actual size of the portrait at the National Portrait Gallery is 28 inches by 31 1/8 inches, whereas Michelle Obama's portrait is 72.1 inches by 60.1 inches. In Parker Looks Up, relative to how Michelle Obama's portrait is illustrated, Reese estimates King's portrait in the book is approximately 72 inches by 36 inches. Although there is a note in the back of the book that the paintings in the book are "reimagined as Parker Curry experienced them during her unforgettable and memorable visit to the National Portrait Gallery and Smithsonian Art Museum," Parker Curry was 2-years-old when she visited the Gallery. To have increased the size of King's portrait relative to Michelle Obama's portrait, in some ways minimizes what impact King's portrait may have had in the context of the story.

Size aside, the most glaring misrepresentation of the portrait in Curry's book was the addition of more feathers on the American Indian men in King's portrait, which were not in the original painting, and which clearly reinforce the stereotype of all American Indians wearing feathers. Feathers carry significant meaning among American Indian communities. Feathers

\footnotetext{
${ }^{3}$ We use "American Indian" to be consistent with the title of Reese's blogspot, American Indians in Children's Literature $(A I C L)$, in which she discusses American Indian imagery and portrayals in children's literature. We recognize others may alternatively prefer Native, Native American, or Indigenous American, and, when possible, the particular tribal name with which one is affiliated (Native Knowledge $360^{\circ} \mathrm{FAQ}, 2020$; Reese, 2019).
} 
were bestowed to members who were particularly valiant in battle or exhibited great sacrifice to defend one's community (Kotrous, 2017). Feathers were also used for ceremonial purposes, such as healing and spiritual rites (Levine, 1991). The number of objects in American Indian rituals have significance, as well (Danchevskaya, 2016). For example, according to the Pawnee Nation of Oklahoma (pawneenation.org), the four prime eagle feathers bear significance, which are attached at the top of the flag to represent the four Pawnee bands: Chaui, Pitahawirata, Skidi and Kitkehahki. Finally, the source of those feathers are important. According to the American Indian Heritage Foundation, feathers from Golden or Bald Eagles signify one of the highest honors that could be received, as American Indians believe eagles have a special connection with the heavens because they fly at very high altitudes ("Feathers," 2018).

In the original portrait by King, the men are wearing eagle feathers on their heads (Smithsonian American Art Museum, 2006). However, Curry (2019) clearly added additional feathers to the men, and feathers that may have come from birds other than eagles. While other bird feathers were used in American Indian ceremonies, they had distinct meanings and were used in deliberately different ways (Levine, 1991). Thus, the addition of the feathers, of arbitrary number and kind, distorts the original portrait, not just in terms of accuracy, but the meaning of what the American Indian men wore. As Reese (2019) asserts, "There is absolutely no reason to lift one marginalized group and misrepresent another." The book unquestionably lifted the image of Black people, and Black women in particular - so much so that it earned a nomination for the NAACP Outstanding Literary Work-Children award in 2020. However, as Reese (2019) exclaims, even the publisher, Simon and Schuster, did not catch the misrepresentation of American Indians. Book award nominees and winners are highly sought after additions to any library collection; nevertheless, it is important to consider the book's explicit and implicit messages on every page, from its words to its illustrations. For example, Caldecott Medal awardee Arrow to the Sun by Gerald McDermott (1975) (see Horning's (2013) and Reese's (2006, 2009) critiques) and New York Times Book Review Best Illustrated Children's Book Awardee, $A$ Fine Dessert, written by Emily Jenkins (2015) and illustrated by Sophie Blackall (see Thomas, Reese, and Horning's (2016) critique), are other examples of books that garnered awards and later received criticism for gross misrepresentations and culturally insensitive depictions. The Transformative Justice Questionnaire identifies these gaps with the following questions: "How would this book look different to varied audiences?"; "Who seems to be the intended audience for this book?"; "Are the author and the illustrator able to speak to the experience depicted in the story, or does the story seem to be written by an outsider looking in?"; "If the author's lived experiences speak to the major parts of the story (\#ownvoices story), are there parts of the story that are not representative of the author's lived experiences? If so, how do we address cultural misrepresentation in this context?"; "Do the illustrations in the book contain stereotypical images or caricatures (e.g., exaggerated features of characters)?"; and "How do the illustrations in the story impact the message of the story?" By reflecting on these questions, educators can 
evaluate the authenticity and accuracy of the story and its illustrations to point out inaccuracies and misrepresentations, whenever possible. For older children, it can also lead to a meaningful conversation about why there may be a disjunct between reality and what is shown in books, television, and other media.

\section{I am Jazz by Jessica Herthel and Jazz Jennings (2014)}

An example of diffractive reading concerning gender identity is the autobiographical children's picture book I am Jazz, written by Jessica Herthel and Jazz Jennings (2014) and illustrated by Shelagh McNicholas. While I am Jazz positively models the transition of Jazz with the support of family and friends, it inadvertently stereotypes gender roles and expressions along a binary, unless there is a critical conversation about how the story is particular to Jazz's experience as a transgender child. As Michael Lovelock (2017) notes, the visibility of trangender people in the media is largely due to the more specific fact that they are celebrities as much as they identify as transgender, which includes Jazz Jennings, Laverne Cox, Janet Mock, and Caitlyn Jenner. The book, while speaking of the transgender experience, reaffirms gendered binaries with lines such as Jazz "having a boy body in a girl brain," and liking pink, singing, make-up, dress-up, and mermaids. Given that the story centers a transgender child and can lead to conversations about being gender-creative, "the unlearning of gender norms, is even more critical than the learning of anti-bias concepts" (Sullivan, 2016, p. 79, emphasis in original). The questions from the Transformative Justice Questionnaire, "What genders are 'normalized' in the book and accepted?"; "How would the book impact a child who does not identify along the traditional gender binary or the gender depicted in the book?"; and "Do the characters depicted in the book conform to or break off from traditional "gender' roles?" allow children to "diffract" from the book to develop a more nuanced understanding of transgender people. Gender color-coded messages are shown to have a strong impact on children's brain development, including the career paths they choose (Anand, 2019). Books such as Julian is a Mermaid, written and illustrated by Jessica Love (2018), and When Aidan Became a Brother, written by Kyle Lukoff (2019) and illustrated by Kaylani Juanita, feature multiple aspects of identity. These books that provide a more intersectional analytic lens are, however, few and far between.

\section{The Ugly Dumpling by Stephanie Campisi (2016)}

A final example of diffractive reading using the transformative justice approach is an analysis of The Ugly Dumpling, written by Stephanie Campisi (2016) and illustrated by Shahar Kober. The Ugly Dumpling is critiqued for its racist depiction of a Chinese restaurant with the main character being a cockroach (Ray, 2020). The book depicts all dumplings as ugly, and the restaurant to be unhygienic with cockroaches and bugs, where the chef and the waiters are Asian, while all the patrons are white. Campisi identifies as white, and the story has multiple instances of stereotyping that are racist. The original Ugly Duckling is, itself, a deeply problematic story in 
which the "duckling" is teased and ostracized on account of being different and only finds acceptance when it transforms into a swan that is recognizable by others.

These examples evince how critically acclaimed books can still fall short, with hidden stereotypes that are easy to overlook, if not read with a transformative justice lens. Implicit bias and social conditioning to stereotypes mean that unless conscious vigilance, critical thinking, and social awareness are developed, it is easy to overlook misrepresentations, inadvertently reinforce stereotypes, and thus perpetuate systemic inequities.

Books written by authors with lived experiences of the characters seem to address some of the challenges with misrepresentation. The rise of the \#ownvoices movement in 2015, started by Corinne Duyvis in response to the lack of books written by authors belonging to non-White groups (https://www.corinneduyvis.net/ownvoices/), has provided much needed attention to bridge the "diversity gap" in children's literature. According to the Cooperative Children's Book Center (CCBC) 2017 Multicultural Statistics (2018), Black, Latinx, and American Indian authors combined wrote just $7 \%$ of new children's books published. Furthermore, only $29 \%$ of books about African/African American people were written by Black authors or illustrators; $34 \%$ of books about Latinx folks were written or illustrated by Latinx people; and $53 \%$ of books with American Indian content/characters were written or illustrated by American Indian creators. This "diversity gap" in publishing leaves out children who are ABIPOC to find adequate representations of themselves in literature (Wenjen, 2018). However, \#ownvoices has also led to some controversy, about the extent to which the entire book must be written from the lived experience of the author. The withdrawal of Kosoko Jackson's Young Adult (YA) novel A Place for Wolves (2019) and Amélie Wen Zhao's Blood Heir (2019) are a couple instances where parts of the story were critiqued for not reflecting the author's own lived experiences (Waldman, 2019). The book Parker Looks Up, as illustrated above, qualifies as a much-needed \#ownvoices book, but at the same time misrepresents American Indian people (Reese, 2019). Clarifying questions raised about \#ownvoices include, do \#ownvoices inadvertently consign authors to write only stories of marginalization, based on their identities? Or when it comes to disability in children's literature, should disclosing disabilities by authors be a prerequisite, or would a story written by caregivers about a non-verbal child qualify as \#ownvoices? Regardless of these questions and controversies, the significance of \#ownvoices cannot be re-emphasized enough.

\section{CONCLUSION}

The transformative justice approach requires an intentional centering of historically disenfranchised identities and a conscious dismantling of unconscious biases that people develop as a result of being exposed to systematic stereotyping of particular people and communities, which are often depicted in media, books, messaging by socializing agents, and other influences. The hope is that this way of thinking will become automatic with more repetition, so that the student and the teacher will become accustomed to inquiring about 
structures of power and privilege that may or may not apply to them. Inviting students' lived experiences as part of the learning process means that ABIPOC students and their cultures are valued, not as tools to teach trauma, but as narratives that celebrate strength, resilience, and resistance. This balance has to be central in the classroom so that the humanity of all children are recognized and respected. Teacher and student, in this sense, do not operate from a hierarchical binary, but as co-learners, bringing in experience and expertise to the common space of the classroom and beyond.

Rudine Sims Bishop (2007) notes that in books written by African American authors, the story "nurtures the souls of Black children by reflecting back to them, both visually and verbally, the beauty and competencies that we as adults see in them" (p. 273). As shown with the book analyses above, despite the increase in the numbers of "diverse" books (School Library Journal, 2019), there are distortions and misrepresentations that are inadvertently incorporated. Again, the question, "who is the intended reader?" becomes important here. Based on Bishop's (1990) distinction of books as "windows, mirrors and sliding doors" for children, Debbie Reese points to "funhouse mirrors" when misrepresentation of American Indian images trivialize, caricature and disrespect when children from those communities read them (School Library Journal, 2019, para. 3). Ebony Elizabeth Thomas goes further to call them "distorted funhouse mirrors of the self" (School Library Journal, 2019, para. 3). Moreover, books that represent one aspect of diversity are often consumed without question and read to children without any critical thinking prompts.

The transformative justice approach is open-ended, in that it factors in systemic barriers that exist in the present to invoke systemic change, while standing within the structures of the US education system and simultaneously dismantling it. This includes the overrepresentation of white teachers in the teaching workforce as the number of ABIPOC students increase (National Center for Education Statistics, 2017), the lack of diversity in the book publishing industry (LeeandLowBooks, 2020), and the lack of representation within children's books (Cooperative Children's Book Center, 2019). With schools being increasingly underfunded (US House of Representatives, 2019), access to books and other resources are further stymied. Our hope is that the transformative justice approach would robustly complicate binaries and foster critical thinking to front and center people's lived experiences, with classrooms becoming co-learning spaces that would lead towards systemic change and from equity to equality.

\section{Acknowledgements}

We are immensely grateful to the staff and students of the former Medford Boys and Girls Club, in Massachusetts, where we were able to conduct children's book readings using the Transformative Justice Questionnaire and whose wisdom and guidance has informed this paper. We also wish to thank Gabrielle Womack for providing invaluable feedback on the manuscript. 


\section{REFERENCES}

Allen, Q., \& White-Smith, K. (2015). "Just as bad as prisons": The challenge of dismantling the school-to-prison pipeline through teacher and community education. Equity and Excellence, 47(4), 445-460. https://dx.doi.org/10.1080/10665684.2014.958961

Anand, D. (2019, December 11). Child's play: Gender, toys, \& career paths. Gaia Connections. http://gaiaconnections.net/2019/12/11/childs-play-gender-toys-and-career-paths-2/

Anand, D. (2020, April 7). Moving beyond equity in education. Charles Hamilton House of Race and Social Justice. https://medium.com/houstonmarshall/moving-beyond-equity-ineducation-eb44e39d19fb

Barad, K. (2007). Meeting the universe halfway: Quantum physics and the entanglement of matter and meaning. Duke University Press.

Baron, A. S., \& Banaji, M. R. (2006). The development of implicit attitudes: Evidence of race evaluations from ages 6, 10 and adulthood. Psychological Science, 17(1), 53-58.

Benard, A. A. F. (2016). Colonizing Black female bodies within patriarchal capitalism: Feminist and human rights perspectives. Sexualization, Media, \& Society, 1-11.

Bilge, S. (2013). Intersectionality undone: Saving intersectionality from feminist intersectionality studies. Du Bois Review: Social Science Research on Race, 10(2), 405424. https://doi.org/10.1017/S1742058X13000283

Bishop, R. S. (1990). Mirrors, windows, and sliding glass doors. Perspectives, 6(3), ix-xi.

Bishop, R. S. (2007). Free within ourselves: The development of African American children's literature. Greenwood.

Campisi, S. (2016). The ugly dumpling. Mighty Media, Inc.

Carter, P. L., Skiba, R., Arredondo, M. I., \& Pollock, M. (2017). You can't fix what you don't look at. Urban Education, 52(2), 207-235. https://doi.org/10.1177\%2F0042085916660350

“CCBC 2017 Multicultural Statistics" (2018, February 22). CCBlogC.

http://ccblogc.blogspot.com/2018/02/ccbc-2017-multicultural-statistics.html

Cooperative Children's Book Center (2019, November 21). Publishing statistics on children's/YA books about People of Color and First/Native Nations and by People of Color and First/Native Nations authors and illustrators.

https://ccbc.education.wisc.edu/books/pcstats.asp

Crenshaw, K. (1990). Mapping the margins: Intersectionality, identity politics, and violence against women of color. Stanford Law Review, 43(6), 1241.

https://doi.org/10.2307/1229039

Curry, J. (2019). Parker looks up. Simon \& Schuster.

Danchevskaya, O. (2016). Numbers in American Indian mythology. Native Leadership: Past, Present, and Future. Proceedings of the Eleventh Native American Symposium, 65-70. Derman-Sparks, L. (2013). An updated guide for selecting anti-bias children's books. Teaching for Change's Bookstore at Busboys and Poets. 
Dunham, Y., Chen, E. E., \& Banaji, M. R. (2013). Two signatures of implicit intergroup attitudes: Developmental invariance and early enculturation. Psychological Science, 24(6), 860868. https://doi.org/10.1177/0956797612463081

Edelman, M. (2006, November/December). Losing the children, early and often. The Crisis Magazine. https://www.childrensdefense.org/wp-content/uploads/2018/08/crisismag-losing-the-children-2007.pdf

Fabelo, P., Thompson, M. D., Plotkin, J., Carmichael, D. P., Marchbanks, P., III, \& Booth, M. (2011). Breaking schools' rules: A statewide study of how school discipline relates to students' success and juvenile justice involvement. New York, NY: Council of State Government Justice Center.

"Feathers" (2018). Indians.org. http://indians.org/articles/feathers.html

Freire, P. (2000). Pedagogy of the oppressed. Continuum. (Original work published 1970).

Gilliam, W. S., Maupin, A. N., Reyes, C. R., Accavitti, M., \& Shic, F. (2016). Do early educators' implicit biases regarding sex and race relate to behavior expectations and recommendations of preschool expulsions and suspensions? Research Study Brief. Yale University, Yale Child Study Center.

Goff, P., Jackson, M., \& Di Leone, B. (2014). The essence of innocence: Consequences of dehumanizing black children. Journal of Personality and Social Psychology, 106(4), 526545. https://doi.org/10.1037/a0035663

Golann, J. W. (2015). The paradox of success at a no-excuses school. Sociology of Education, 88(2), 103-119. https://doi.org/10.1177/0038040714567866

Gorski, P. (2019, April). Avoiding racial equity detours. Educational Leadership, 76(7), 56-61. http://www.ascd.org/publications/educationalleadership/apr19/vol76/num07/Avoiding-Racial-Equity-Detours.aspx

Gorski, P. C., \& Pothini, S. G. (2018). Case studies on diversity and social justice education (2nd ed.). Routledge.

Gregory, A., \& Mosely, P. M. (2004). The discipline gap: Teachers' views on the overrepresentation of African American students in the discipline system. Equity \& Excellence in Education, 37(1), 18-30. https://doi.org/10.1080/10665680490429280

Gregory, A., Skiba, R. J., \& Noguera, P. A. (2010). The achievement gap and the discipline gap: Two sides of the same coin? Educational Researcher, 39(1), 59-68.

https://doi.org/10.3102\%2F0013189X09357621

Gregory, A., \& Thompson, A. R. (2010). African American high school students and variability in behavior across classrooms. Journal of Community Psychology, 38(3), 386-402. https://doi.org/10.1002/jcop.20370

Gullo, G. L. (2017). Implicit bias in school disciplinary decisions (Order No. 10278566). Available from ProQuest Dissertations \& Theses Global (1915005969). https://search-proquestcom.proxy-remote.galib.uga.edu/docview/1 915005969?accountid=14537 
Heissel, J. A., Levy, D. J., \& Adam, E. K. (2017). Stress, sleep, and performance on standardized tests: Understudied pathways to the achievement gap. AERA Open, 3(3). https://doi.org/10.1177\%2F2332858417713488

Herthel, J., \& Jennings, J. (2015). I am Jazz. Penguin Young Readers Group.

Hill, C. M. (2017). More-than-reflective practice: Becoming a diffractive practitioner. Teacher Learning and Professional Development, 2(1), 1-17.

Horning, K. T. (2013). Arrow to the Sun and critical controversies. The Horn Book Magazine, 5, 35-41. https://www.hbook.com/?detailStory=arrow-to-the-sun-and-criticalcontroversies

Howard, T. C. (2001). Powerful pedagogy for African American students: A case of four teachers. Urban Education, 36(2), 179-202.

Jemal, A. (2017). Critical consciousness: A critique and critical analysis of the literature. The Urban Review, 4(4). https://doi.org/10.1007/s11256-017-0411-3

Jenkins, E. (2015). A fine dessert. Random House Children's Books.

Katz, K. (1999). The colors of us. Henry Holt and Company.

Kotrous, N. (2017). Plains Indians. Nebraska Department of Education.

https://www.education.ne.gov/wp-content/uploads/2017/07/Plains Indians.pdf

LeeandLowBooks (2020, January 28). Where is the diversity in publishing? The 2019 diversity baseline survey results. The Open Book Blog.

https://blog.leeandlow.com/2020/01/28/2019diversitybaselinesurvey/

Levine, V. L. (1991). Feathers in Southeast American Indian ceremonialism. Expedition Magazine, 33(2), 3-11.

Levy, D. J., Heissel, J. A., Richeson, J. A., \& Adam, E. K. (2016). Psychological and biological responses to race-based social stress as pathways to disparities in educational outcomes. American Psychologist, 71(6), 455-473.

https://psycnet.apa.org/doi/10.1037/a0040322

Love, B. L. (2014). "I see Trayvon Martin": What teachers can learn from the tragic death of a young Black male. The Urban Review, 46(2), 292-306. https://doi.org/10.1007/s11256$\underline{013-0260-7}$

Love, J. (2018). Julian is a mermaid. Candlewick Press.

Lovelock, M. (2017). "I Am...": Caitlyn Jenner, Jazz Jennings and the cultural politics of transgender celebrity. Feminist Media Studies, 17(5), 737-754.

https://doi.org/10.1080/14680777.2017.1298649

Lukoff, K. (2019). When Aidan became a brother. Lee and Low Books Inc.

Mallapragada, M. (2016). Curry as code: Food, race, and technology. In S. Davé, L. Nishime, \& T. Oren (Eds.), Global Asian American popular cultures (pp. 263-275). NYU Press. jstor.org/stable/j.ctt18040jc.21 
Maroney, S. R. (2011). "To Make a Curry the India Way": Tracking the meaning of curry across eighteenth-century communities. Food and Foodways, 19(1-2), 122-134.

https://doi.org/10.1080/07409710.2011.544208

McDermott, G. (1974). Arrow to the sun. Puffin Books.

McNeal, L. R. (2016). Managing our blind spot: The role of bias in the school-to-prison pipeline. Arizona State Law Journal, 48, 285-310.

Morris, E. W., \& Perry, B. L. (2017). Girls behaving badly? Race, gender, and subjective evaluation in the discipline of African American girls. Sociology of Education, 90(2), 127-148. doi:10.1177/0038040717694876

National Center for Education Statistics (2017). Table 209.10: Number and percentage distribution of teachers in public and private elementary and secondary schools, by selected teacher characteristics: Selected years, 1987-88 through 2015-16. https://nces.ed.gov/programs/digest/d17/tables/dt17_209.10.asp?current=yes

Native Knowledge $360^{\circ} \mathrm{FAQ}$ (2020). National Museum of the American Indian. https://americanindian.si.edu/nk360/faq/did-you-know

Okonofua, J. A., \& Eberhardt, J. L. (2015). Two strikes: Race and the disciplining of young students. Psychological Science, 26(5), 617-624.

https://doi.org/10.1177/0956797615570365

Over, H., \& McCall, C. (2018). Becoming us and them: Social learning and intergroup bias. Social and Personality Psychology Compass, 12(4), e12384.

https://doi.org/10.1111/spc3.12384

Raabe, T., \& Beelmann, A. (2011). Development of ethnic, racial, and national prejudice in childhood and adolescence: A multinational meta-analysis of age differences. Child Development, 82, 1715-1737. https://doi.org/10.1111/j.1467-8624.2011.01668.x

Ray, A. (2020). Don't yuck my yum: Kids books that dismantle anti-Asian racism. Raising Luminaries. https://booksforlittles.com/orientalism-food-shaming/

Reese, D. (2006). American Indians in Children's Literature. https://americanindiansinchildrensliterature.blogspot.com/

Reese, D. (2006, October 25). Gerald McDermott's Arrow to the Sun. American Indians in Children's Literature.

https://americanindiansinchildrensliterature.blogspot.com/2006/10/geraldmcdermotts-arrow-to-sun-

gerald.html\#: :text=American\%20Indians\%20in\%20Children's\%20Literature,Dr.

Reese, D. (2009, April 6). Discussion guide to Arrow to the Sun. American Indians in Children's Literature.

https://americanindiansinchildrensliterature.blogspot.com/2009/04/scholastic-guideto-arrow-to-sun.html

Reese, D. (2019, December 14). Not recommended: Parker Looks Up by Parker Curry, Jessica Curry; illustrated by Brittany Jackson. American Indians in Children's Literature. 
https://americanindiansinchildrensliterature.blogspot.com/2019/12/notrecommended-parker-looks-up-by.html

School Library Journal (2019, June 19). An updated look at diversity in children's books.

https://www.slj.com/?detailStory=an-updated-look-at-diversity-in-childrens-books

Schuessler, J. (2015, November 6). 'A fine dessert': Judging a book by the smile of a slave. New York Times. https://www.nytimes.com/2015/11/07/books/a-fine-dessert-judging-abook-by-the-smile-of-a-slave.html

Skiba, R. J. (2015). Interventions to address racial/ethnic disparities in school discipline: Can systems reform be race-neutral? In R. Bangs, L. E. Davis, R. Bangs, \& L. E. Davis (Eds.), Race and social problems: Restructuring inequality (pp. 107-124). Springer Science + Business Media.

Skiba, R. J., Horner, R. H., Chung, C.-G., Rausch, M. K., May, S. L., \& Tobin, T. (2011). Race is not neutral: A national investigation of African American and Latino disproportionality in school discipline. School Psychology Review, 40, 85-107.

Smith-Maddox, R., \& Solórzano, D. G. (2002). Using critical race theory, Paulo Freire's problemposing method, and case study research to confront race and racism in education. Qualitative Inquiry, 8(1), 66-84. https://doi.org/10.1177\%2F107780040200800105 Smithsonian American Art Museum (2006). Young Omahaw, War Eagle, Little Missouri, and Pawnees. https://americanart.si.edu/artwork/young-omahaw-war-eagle-littlemissouri-and-pawnees-13740

Staats, C. (2014). Implicit racial bias and school discipline disparities (special rep.). Kirwan Institute.

Sullivan, A. L. (2016). Kindergartners studying trans* issues through I am Jazz. In s.j. Miller (Ed)., Teaching, affirming, and recognizing trans and gender creative youth (pp. 63-80). Palgrave Macmillan.

Thomas, E. E., Reese, D., \& Horning, K. T. (2016). Much ado about $A$ fine dessert: The cultural politics of representing slavery in children's literature. Journal of Children's Literature, 42(2), 6-17.

US House of Representatives (2019, February 12). Underpaid teachers and crumbling schools: How underfunding public education shortchanges America's students. Hearing before the Committee on Education and Labor, U.S. House of Representatives, One Hundred Sixteenth Congress, First Session. Serial Number 116-3.

Waldman, K. (2019, March 21). In Y.A., where is the line between criticism and cancel culture? The New Yorker. https://www.newyorker.com/books/under-review/in-ya-where-is-theline-between-criticism-and-cancel-culture

Welsh, R. O., \& Little, S. (2018). The school discipline dilemma: A comprehensive review of disparities and alternative approaches. Review of Educational Research, 88(5), 752-794.

Wenjen, M. (2018, June 6). \#OwnVoices Controversy. Pragmatic Mom. https://www.pragmaticmom.com/2018/06/ownvoices-controversy/ 
Williams, A., \& Steele, J. R. (2019). Examining children's implicit racial attitudes using exemplar and category-based measures. Child Development, 90(3), e322-

e338. https://doi.org/10.1111/cdev.12991

Williams, P. J. (1991). The alchemy of race and rights. Harvard University Press.

York, S. (2016). Roots and wings: Affirming culture and preventing bias in early childhood. Redleaf Press. 